Received: August 25, 2017

Revision received: March 15, 2018

\title{
Talent Co-education Performance Mechanism in Fujian and Taiwan Universities
}

\author{
Deyi Kong ${ }^{1}$ \\ College of Business Administration
}

\begin{abstract}
This paper builds a co-education performance mechanism model with universities' overall strength, quality of students and organizational management as independent variables, talent co-education performance in Fujian and Taiwan universities as dependent variables, and the co-education extent as intervening variable. A questionnaire survey is conducted to access truthful data for empirical study carried out by using the structural equation model. The findings reveal that the overall strength, the quality of students, the organizational management all have a significantly positive correlation with the talent co-education performance in Fujian and Taiwan universities, where the co-education extent plays an intermediation effect. To enhance the strength of universities, it is required to select appropriate partners, intensify the policy support, macroeconomic regulation and control of the government, imbue students with right ideas, motivate them in learning, blend co-education concepts into pedagogical practices, rationalize the management system; build up communication channels and facilitate a deep integration.
\end{abstract}

\section{Keywords}

Talent Co-education Performance • Talent Co-education • Universities

\footnotetext{
*This work is supported by the project for "National Education Science "13th Five-Year Plan" 2017 Ministry of Education Youth Project": The Influence of the Matching Degree of College Tutors and Postgraduates on the Cultivation of Innovative Talents and the Countermeasures (EIA170466), Project leader: Chen Youcheng; Scientific Research Program of the 13th five year plan of education science in Fujian province: problem oriented, coordinated and co-promoted, building a new system of innovation and entrepreneurship education (FJJKCG18-016), Project leader: Kong Deyi.

${ }^{1}$ Correspondence to: Deyi Kong $(\mathrm{PhD})$, College of Business Administration, Fujian Jiangxia University, Fuzhou 350108, China. Email: 170584101@qq. com

Citation: Kong, D. Y., Talent Co-education Performance Mechanism in Fujian and Taiwan Universities. Educational Sciences: Theory \& Practice, 18(5), 1112-1124. http://dx.doi.org/10.12738/estp.2018.5.013
} 
The talent co-education of universities in Fujian and Taiwan is a talent training mode that can enable the sharing of top-quality resources across both sides of the Taiwan Straits under the background of "One China". Talent co-education in Fujian and Taiwan universities has its macro background. The Opinions on Supporting Fujian Province to Accelerate the Construction of the Economic Zone on the West Coast of the Taiwan Straits issued by the State Council as early as 2009 undermines that Fujian should give play to its unique advantages towards Taiwan and intensifies cultural exchange between both sides, and establishes the demonstration and the pioneering areas for the exchange of higher education across the Taiwan Straits. (Xiao, 2009) The Fujian Province Implements the 'Opinions on Supporting Fujian Province to Accelerate the Construction of the Economic Zone on the West Coast of the Taiwan Straits' Implementation Opinions further stresses that Fujian Province should actively carry out joint school-running pilot programs, and effectively promote the enrollment, mutual recognition of credit and reciprocal employment of teachers in Fujian and Taiwan, so as to continuously expand the talent co-education in universities (Chu, Zheng \& Li, 2015). Currently, the increasingly close crossstrait relations have created a more harmonious environment for cooperation and common education, and the increasingly flexible cross-strait education policies have also provided good conditions for cooperation and coeducation. The cross-strait tourism policies successively issued have accelerated the development of two-way exchanges between the two sides of the Taiwan Straits (Lian, Huang \& Zhuang, 2018). The number of coeducation talents in universities in Fujian and Taiwan is increasing, and the enrollment scale has also enlarged rapidly. According to incomplete statistics, 70 of the 89 universities in Fujian participate in the co-education model for talents, in which $83.78 \%$ are the undergraduates, and $75 \%$ are junior college students; $65.19 \%$ of the 158 universities in Taiwan participate in this mode.

Common education for talents in Fujian and Taiwan universities is not only an integral part of talent cultivation but also a crucial means to enhance human capitals. It can greatly improve students' skills and qualities to contribute much in economic growth. At a conceptual level, the co-cultivation of talents derives from the old ideas such as "cooperative education", "co-culture" and "combination of production, education and scientific research". With the development of the times, the concept of talent co-education has been deeply infiltrated into the academic circle. After the 19th CPC National Congress, the co-education model for talents has been blended with more meanings such as "sharing", "collaboration" and "community". There are two talent co-education models in Fujian and Taiwan universities, one is the "segmental integration" joint coeducation project, which mainly implements " $3+1$ " and " $4+0$ " projects in public undergraduate universities; the other is joint co-education project "interschool business", where the specialized colleges relying on enterprises explore the "1+1+1" model with Taiwanese vocational colleges (Yan, 2016). Some scholars have subdivided the "segmented integration" into the "splicing mode" and "segment mode" (Qian, 2014). There is also short dated one, the "exchange student" model, which means that universities in Fujian and Taiwan conclude the interschool exchange and cooperation agreements to dispatch outstanding students for short-term exchange learning and elective credits with mutual recognition (Zhang, 2018). For example, Xiamen University and Taiwan University of Political Science have signed an agreement involving exchange students; Taiwan's Chung Hsing University and Fujian Agriculture and Forestry University, Tainan University of Applied Sciences and Minjiang College have reached an agreement on talent co-education and developed a co-education program. 
With the deepening development of talent co-education in Fujian and Taiwan universities, the talent quality of co-education has aroused widespread concern in the social and academic circles. They cling to an eternal pursuit of improving the quality of talent cultivation, which also matters the utilization and benefits of the coeducation resources (Chen, Pan \& Yang, 2013). Therefore, under the social background, it is apparently necessary to explore the impact mechanism of talent co-education performance.

\section{Literature review and theoretical hypothesis}

\section{University strength}

Knowledge potential refers to the position of the knowledge body in the process of cooperation according to the different depth and breadth of knowledge energy state (Guo, Liu \& Guo, 2014).Two important factors are the quantitative knowledge and the knowledge quality. Different universities stay at different position potentials due to the obvious difference in retained quantity and quality of knowledge. Among the partners selected, the correlation between two partners at the knowledge and strength levels plays an important role. Two parties are often universities with high knowledge potentials such as knowledge reserve, R\&D capacity, and faculty quality. Universities have included capacity matching, resource matching, and complementary compatibility as factors affecting the success of both parties (Liu, 2017). Zhu, Chen, Cai \& Qian, (2014) made an analysis by the structural equation modeling and believed that the overall knowledge of universities has an indirect effect on talent co-education. It also has a certain promotion effect on it. Chu and $\mathrm{Li},(2016)$ argued that teachers, as direct participants in the cooperation between Fujian and Taiwan, have a direct bearing on the quality and operation of co-education model in Fujian and Taiwan universities. On this basis, this paper proposes the following assumptions:

H1: The strength of universities is positively correlated to the co-education performance in Fujian and Taiwan universities.

\section{Quality of students}

In the cooperation between universities in Fujian and Taiwan, the most important subject is the students. Talent cultivation is a process in which the students as a main body are self-learning under the guidance of teachers in an academic atmosphere just like universities. Students in Fujian and Taiwan have their own characters, for example, they are not solid in cultural base, lack of awareness for self-discipline, but they have cheerful personality and stronger social skills. Students' educational level, learning skills and learning motivation and other factors will affect the performance of co-education model in Fujian and Taiwan universities. Chen et al., (2015) conducted a survey among exchange students from five universities in Fujian, and found that the individual driving force, learning skills, and the guidance and supervision from universities during the exchange period are important factors that affect the quality of exchange training in Taiwan. Chu and Li believed that students, as specific co-education and service objects, play a role for evaluating and supervising concrete operation of cooperation between Taiwan and Taiwan. Lv (2016) stated particularly in the 
long-term mechanism establishment of talent cultivation that a student management system shall be set up for cooperation model between Fujian and Taiwan universities, and effectively motivate students to accept right ideas. Therefore, this paper proposes the following assumptions:

$\mathrm{H} 2$ : The quality of students is positively correlated to the co-education performance in universities in Fujian and Taiwan.

\section{Organizational management}

In the co-education system of universities in Fujian and Taiwan, organizational management may be dominant since it will standardize the whole system and its concrete operations, and in a general direction, coordinate cultures and systems to reach an agreement on co-education between two sides. Detailed framework covers the curriculum setup, teaching methods, textbooks and others in every regard. It underlies the talent coeducation. Chen et al., proposed that how to blend cross-strait systems and cultures is more challenging for the talent co-education in Fujian and Taiwan. To react to this challenge, effectively improve the co-education performance, it is required to repeatedly communicate with each other in the selection of teaching materials and curriculum setup. Only in this way can a cross-strait education community be established (Wang, Jiang, Zhu \& $\mathrm{Xu}, 2018)$. In the study, scholars also particularly stressed that there is a need to improve the talent co-education performance from co-education program, characteristic textbook, teaching management, interactive network, and support system such as project funds. Liu and Lin (2014) proposed that, if cross-strait universities have not reached an underlying agreement, the talent co-education performance will be greatly spoiled. Therefore, this paper proposes the following assumptions:

H3: Organizational management is positively correlated to the co-education performance of talents in universities in Fujian and Taiwan.

\section{Intermediation effect of the co-education extent}

The success of talent co-education in Fujian and Taiwan universities, for the most part, depends on the coeducation extent, that is, whether the co-education objective of the two sides has reached a consensus, whether the universities in the two sides complement each other, learn from each other, and whether the communication and coordination mechanism between the two works smoothly during co-education process. The choice of cooperative universities in many ways is the guarantee for improving the performance of talent co-education, while the strength of universities and the quality of students are essential concerning factors. Chu and $\mathrm{Li}$ (2016), from the perspective of universities in Fujian Province, believe that the original intentions and the interest appeal of public and private universities for the selection of talents are different. Public universities may pursue for more diverse interests, for example, promote cross-strait exchanges, introduce high-quality resources, improve the economic benefits, while private universities mainly intend to profit much. Different intentions will lead the two sides to laying different stresses on knowledge potential, $R \& D$ strength, and quality of students. There are also differences in the enthusiasm for co-education. Li and Li (2017) draw on the Logistic model of universities' 
knowledge triangles, and from the perspective of students' common education in universities, they believe that the co-education extent between universities can expedite the organic integration of knowledge resources and talents in universities. The performance of talent co-education in Fujian and Taiwan universities requires cooperative entities to create dynamic complementary structures. Therefore, this paper proposes the following assumptions:

H4: The co-education extent plays an intermediation effect between the universities' strength and the performance of talent co-education in universities

H5: The co-education extent plays an intermediation effect between the quality of students and the performance of talent co-education in Fujian and Taiwan universities

In view of the disparities in the systems and cultures between both sides, the linkage mechanism for the cooperation with Taiwan universities is an important guarantee for the development of talent co-education. Effective communication is the key to promoting the high-level operation of the co-education mechanism, that is, the communication mode for O\&M depends on different degree of co-education relationship. Universities in Fujian and Taiwan should use the interactive network as the link, set up the "inter-connectivity" education, strengthen the co-education extent, and improve the effectiveness of talent co-education in Fujian and Taiwan universities. In terms of the talent co-education mode, textbook selection, curriculum setting, system design, etc., joint development level between the two determines how well the performance of talent co-education comes out in the later stage. Therefore, this paper proposes the following assumptions:

H6: The co-education extent plays a intermediation effect in O\&M and the performance of talent coeducation in universities

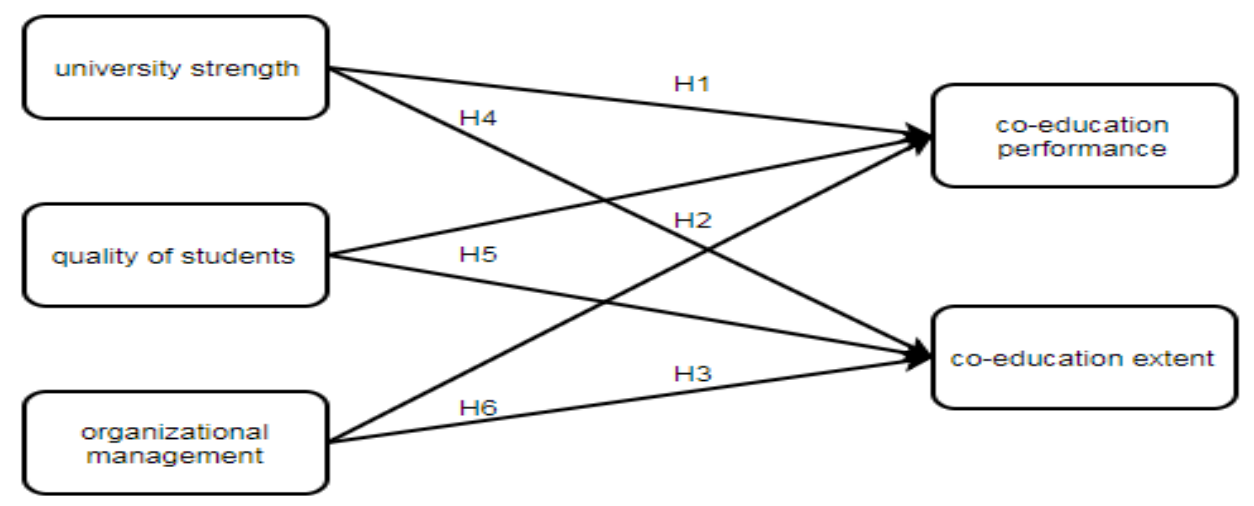

Figure 1. Study model

\section{Study model}

Under the policy environment, the talent co-education, relying on universities, encourages both sides to have an organic integration in the elements of educational resources, deeply interact with each other, enhance the 
performance of talent co-education, and effectively improve the quality of students. University strength, quality of students, and O\&M are important factors that affect the co-education performance. The co-education extent determines the impact path between the two. This paper focuses on the intervening effect of the co-education extent among the three factors. Therefore, the study model of this paper is shown in Fig. 1.

\section{Study design}

\section{Data collection}

The students who have participated in the cooperation between Fujian and Taiwan university in Fujian Province as the survey object. As they are involved in the talent co-education system, their opinions are representative. Through the field interviews and a total of 350 electronic questionnaires distributed among them from July 2018 to September 2018, 350 questionnaires have been actually collected, exclusive of obviously incorrect and incompletely answered ones, a total of 292 valid questionnaires are finally retrieved, and the effective recovery rate is $83.43 \%$.

\section{Variable measurement}

This paper has a design based on the existing literature and some maturity scales. Based on the interviews and pre-survey results, the items and measures are improved. The body of the questionnaire is evaluated using the Likert five-level scale, with 1-5 scores representing very disagree, disagree, common, agree and very agree, respectively.

Independent variable. The variable measurement of the university strength is mainly based on the viewpoints of Zhu Guanghua and Chu Deping. The quality of teachers, the R\&D level, and the training funds are chosen as the observation indicators of this paper. The variable measurement of the source quality is mainly based on the viewpoints of Chen Yanling and Lu Yingfang, and the students' education level, learning competences and learning drive force are regarded as observation indicators. The variable measurement of O\&M is mainly based on the viewpoints of Zhao Liming, Liu Xianchang, Lin Renzao, and Zeng Xiuyun choosing three observation indicators: curriculum setting, training method and organizational system.

Intermediary variables. The variable measurement of the co-education extent is mainly based on the viewpoints of Guo Yan, Wang Qiliang, Gao Wei et al., Combining the specific situation of the universities, the objective compatibility, the complementarity of advantages and the communication coordination are chosen as the observation indicators.

Dependent variable. The variable measurement of talent co-education performance in Fujian and Taiwan universities is mainly based on the viewpoints of Xu Heqing and Hu Zuguang. The training scale, practical learning enthusiasm and students' comprehensive quality are taken as the observation indicators of this paper. 


\section{Sample reliability and validity}

Confirmatory factor analysis is performed on 292 samples using structural equation model software (LISREL 8.70). The normalized factor load coefficient of each latent variable measurement item falls within $0.65 \sim 0.88$ at a highly significance level; the load values are all greater than 0.5 , which shows that the measurement model project in this study has a better quality. The Combined Reliability (CR) and Cronbach's $\alpha$ (as shown in Table 1) of each latent variable are both greater than the critical value of 0.6 , which implies that the questionnaire survey has a good reliability.

Table 1

\begin{tabular}{|c|c|c|c|c|c|c|}
\hline LV & CR & Cronbach's $\alpha$ & AVE & OI & SFL $(\lambda)$ & $\mathrm{RV}(1-\lambda 2)$ \\
\hline \multirow{4}{*}{ Co-education performance } & \multirow{4}{*}{.7856} & \multirow{3}{*}{.786} & \multirow{3}{*}{.5517} & Y1 & .78 & .40 \\
\hline & & & & Y2 & .79 & .38 \\
\hline & & & & Y3 & .65 & .58 \\
\hline & & & \multirow{4}{*}{.6246} & M1 & .81 & .34 \\
\hline \multirow[t]{3}{*}{ Co-education extent } & \multirow[t]{3}{*}{.833} & \multirow[t]{3}{*}{.837} & & M2 & .80 & .36 \\
\hline & & & & M3 & .76 & .42 \\
\hline & & & & A1 & .81 & .35 \\
\hline \multirow[t]{3}{*}{ University strength } & \multirow[t]{3}{*}{.8752} & \multirow[t]{3}{*}{.878} & \multirow[t]{2}{*}{.7006} & A2 & .87 & .25 \\
\hline & & & & A3 & .83 & .32 \\
\hline & & & & B1 & .88 & .23 \\
\hline \multirow[t]{3}{*}{ Quality of students } & \multirow[t]{3}{*}{.8899} & \multirow[t]{3}{*}{.896} & \multirow[t]{3}{*}{.7296} & B2 & .88 & .23 \\
\hline & & & & B3 & .80 & .36 \\
\hline & & & & $\mathrm{C} 1$ & .81 & .34 \\
\hline \multirow[t]{2}{*}{ Organizational management } & \multirow[t]{2}{*}{.8603} & \multirow[t]{2}{*}{.862} & \multirow[t]{2}{*}{.6725} & $\mathrm{C} 2$ & .83 & .31 \\
\hline & & & & $\mathrm{C} 3$ & .82 & .33 \\
\hline
\end{tabular}

The confirmatory factor analysis continues to test the scale. In accordance with the recommendations of the discriminant validity verification given by Anderson \& Gerbing (1988), as shown in Table 2, the correlation coefficient between latent variables is $0.531 \sim 0.739$, and the confidence interval of each correlation coefficient (correlation coefficient $\pm 1.96 \times$ standard error) are less than 1 , which shows that the concepts of individual latent variables are independent of each other, and the questionnaire has a good discrimination validity.

The convergent validity is mainly to evaluate the consistency degree between all the measurement items. AVE represents the common mutation between the latent variable and the measurement item. If AVE $>0.50$, it means that in the mutation of the measurement item, if the portion explainable by the factor is greater than that caused by the measurement error, it means that the measurement variable scale has a convergent validity. Discriminant validity represents such a behavior that the degree of difference between items of these constructs are measured respectively due to different constructs. $\varphi 2$ represents the common mutation between factors (potential variables). If $\mathrm{AVE}>\varphi 2$, it means that the common mutation between the factor and measurement item is greater than that between factors, that is, there is a discriminate validity between the measurement variable scales. Hair et al., suggest that the square root of mean mutation extraction content and correlation coefficient of individual variables are used to replace the comparison between AVE and $\varphi 2$. As shown in Table 1 , the mean mutation extraction contents of individual variables are all greater than 0.50 , which implies that the questionnaire scale has a high convergent validity; in addition, the square root of the mean variation extraction content of individual variables falls within $0.743 \sim 0.854$, all of which are greater than the correlation coefficient between the variables. It turns out that the questionnaire scale has a higher discriminant validity. As above, the 
measurement variable scale in the study has a higher validity and can accurately measure the true meaning of each variable.

Table 2

Correlation Coefficient and Validity Test Between Individual Variables

\begin{tabular}{|c|c|c|c|c|c|}
\hline Variable & $\mathrm{Y}$ & $\mathrm{M}$ & $\mathrm{A}$ & $\mathrm{B}$ & $\mathrm{C}$ \\
\hline $\mathrm{Y}$ & 1.000 & & & & \\
\hline M & $\begin{array}{c}0.739 * * * \\
(0.042)\end{array}$ & 1.000 & & & \\
\hline A & $\begin{array}{c}0.722 * * * \\
(0.041)\end{array}$ & $\begin{array}{c}0.701 * * * \\
(0.041)\end{array}$ & 1.000 & & \\
\hline B & $\begin{array}{c}0.676^{* * *} * \\
(0.044)\end{array}$ & $\begin{array}{c}0.604 * * * \\
(0.047)\end{array}$ & $\begin{array}{c}0.531 * * * \\
(0.050)\end{array}$ & 1.000 & \\
\hline $\mathrm{C}$ & $\begin{array}{c}0.718 * * * \\
(0.042)\end{array}$ & $\begin{array}{c}0.695 * * * \\
(0.042)\end{array}$ & $\begin{array}{c}0.650 * * * \\
(0.043)\end{array}$ & $\begin{array}{c}0.672 * * * \\
(0.041)\end{array}$ & 1.000 \\
\hline
\end{tabular}

Note. ${ }^{*}, * *, * * *$ indicate $\mathrm{p} \leq 0.05, \mathrm{p} \leq 0.01, \mathrm{p} \leq 0.001$, respectively; parentheses indicate the standard error.

\section{Analysis of empirical results}

According to the hypothesis, the structural equation model software (LISREL 8.70) is used to build the structural equation model which can access the relationships of the university strength, source quality, O\&M and talent co-education in universities. The fit indices of model are shown in Table 3. $\chi 2(48)=101.82$, $\chi 2 / \mathrm{df}=2.1<5, \mathrm{RMSEA}=0.0621<0.08$, other fit indices NFI, RFI, IFI, TLI, CFI, etc., are all greater than the critical value of 0.9. All indices fall within a reasonable distribution range of fit reference indices, which suggests that this model has a good fit effect. The model test results show that university strength $(\gamma=0.39$, $\mathrm{t}=5.24>1.96)$, source quality $(\gamma=0.28, \mathrm{t}=3.78>1.96), \mathrm{O} \& \mathrm{M}(\gamma=0.27, \mathrm{t}=3.09>1.96)$ have a significantly positive impact on the talent co-education. Assume $\mathrm{H} 1, \mathrm{H} 2$, and $\mathrm{H} 3$ are supported.

Table 3

List of Individual Fit Indices of the Model

\begin{tabular}{lccccccccc}
\hline fit index & $\chi^{2}$ & df & $\chi^{2} / \mathrm{df}$ & RMSEA & NFI & RFI & IFI & TLI & CFI \\
\hline RV & & & $2-5$ & $<0.08$ & $>0.9$ & $>0.9$ & $>0.9$ & $>0.9$ & $>0.9$ \\
EV & 101.82 & 48 & 2.1 & 0.0621 & 0.980 & 0.972 & 0.990 & 0.986 & 0.990 \\
\hline
\end{tabular}

According to the intervening effect test practice proposed by Wen and Ye (2014), the structural equation intervening effect test model is built for the relationship between the university strength, the quality of students, the O\&M and talent co-education performance, in which the fit indices are shown in Table 4. The model standardization path coefficients are shown in Table 5.

Table 4

List of Fit Indices for the Intervening Effect Test Model

\begin{tabular}{lccccccccc}
\hline Fit index & $\chi^{2}$ & $\mathrm{df}$ & $\chi^{2} / \mathrm{df}$ & RMSEA & NFI & RFI & IFI & TLI & CFI \\
\hline $\mathrm{EV}$ & 151.93 & 80 & 1.9 & 0.0556 & 0.980 & 0.974 & 0.991 & 0.989 & 0.991 \\
\hline
\end{tabular}

As shown in Table 4, $\chi 2(80)=151.93, \chi 2 / \mathrm{df}=1.9<5$, RMSEA $=0.0556<0$, other fit indices NFI, RFI, IFI, TLI, CFI, etc., are all greater than the critical value of 0.9. All indices fall in the range of reasonable distribution values of the model fit reference indices, which shows that the study model has a good fit effect. 
Table5

Standardization Path Coefficient of Intervening Effect Test Model

\begin{tabular}{lcc}
\hline Path & Standardized path coefficient & T-value \\
\hline $\mathrm{A} \rightarrow \mathrm{Y}$ & .29 & 3.52 \\
$\mathrm{~B} \rightarrow \mathrm{Y}$ & .24 & 3.20 \\
$\mathrm{C} \rightarrow \mathrm{Y}$ & .19 & 2.08 \\
$\mathrm{~A} \rightarrow \mathrm{M}$ & .40 & 5.29 \\
$\mathrm{~B} \rightarrow \mathrm{M}$ & .18 & 2.43 \\
$\mathrm{C} \rightarrow \mathrm{M}$ & .31 & 3.49 \\
$\mathrm{M} \rightarrow \mathrm{Y}$ & .26 & 2.81 \\
\hline
\end{tabular}

As shown in Table 5, the standardization path coefficient of the university strength vs. co-education extent is $0.40(\mathrm{t}=5.29>1.96)$, while the standardized path coefficient of the co-education extent vs. on talent coeducation performance is $0.26(\mathrm{t}=2.81>1.96)$. Both reaches $95 \%$ significance level. The standardization path coefficient of university strength vs. talent co-education performance is $0.29(\mathrm{t}=3.52>1.96)$, also reaching $95 \%$ significance level, which indicates that the co-education extent plays a partial intermediary role between the university strength and education performance, assume $\mathrm{H} 4$ is supported.

The standardized path coefficient of the source quality vs. the co-education extent is $0.18(\mathrm{t}=2.43>1.96)$, and the standardized path coefficient of the co-education extent vs. the talent co-education performance is 0.26 $(\mathrm{t}=2.81>1.96)$. Both reach $95 \%$ significance level; the standardized path coefficient of student source quality vs. talent co-education performance is $0.24(\mathrm{t}=3.20>1.96)$, also reaching $95 \%$ significance level, which shows that the co-education extent plays a partial intermediary role between student source quality and talent coeducation performance. Assume H5 is supported.

The standardized path coefficient of the O\&M vs. the co-education extent is $0.31(\mathrm{t}=3.49>1.96)$, and the standardized path coefficient of the co-education extent vs. talent co-education is $0.26(\mathrm{t}=2.81>1.96)$; both reach 95\% significance level; the standardized path coefficient of the O\&M vs. talent co-education performance is $0.19(\mathrm{t}=2.08>1.96)$, also reaching $95 \%$ significance level, which implies that the co-education extent plays a partial intermediary role between the O\&M and the talent co-education performance. Assume H6 is supported.

\section{Conclusion}

University strength, student source quality, and O\&M have a positive impact on the talent co-education performance, and each factor has a different impact path. This coincides with the original assumptions. There is a direct effect coefficient 0.29 between the university strength and the talent co-education performance, 0.24 between student quality and the talent co-education performance, 0.19 between the O\&M and the talent coeducation performance, which suggests that, in the talent co-education system in universities, whether it is the participant entity (universities, students), or system specification (including curriculum settings, training programs), they are all positively correlated to the talent co-education performance. The talent co-education performance has a direct bearing on the knowledge reserve, teacher quality and R\&D level of universities. When the university strength gets stronger, the talent co-education performance in universities in Fujian and Taiwan 
is higher. Similarly, the stronger the students' learning competences and initiatives and the more perfect, standardized and detailed the organization management system, the higher the performance of talent coeducation.

In addition to the impact from the university strength, the quality of the students, the O\&M themselves, they play an indirect driving role in improving the co-education performance via co-education extent. The coeducation extent is divided into three dimensions, namely, target compatibility, complementarity to each other, and communication coordination. The findings show that in the talent co-education system involved by many parties in Fujian and Taiwan universities, the two sides choose the cooperative co-education on the grounds that objectives are consistent and compatible, the universities can complement each other in all ways, and that there is a smooth communication mechanism in the whole system. When universities in Fujian and Taiwan choose talents, they will access the university strength, the quality of students and the organization and management capacities. However, it is more important to consider the fit of both. The best is not always the most suitable. How well the talent co-education performance looks often means whether the co-education extent is better. The construction of good communication mechanism is an important guarantee mechanism for improving the talent co-education performance among students in Fujian and Taiwan universities. Through communication and coordination, teachers from Fujian and Taiwan universities can timely know about the students' learning and living conditions, and supervise and get familiar with these in order to make sure that students from Fujian and Taiwan reach the co-education objectives and tasks.

\section{Enlightenments}

Improve the overall strength of universities, choose the right partner. The ultimate purpose of talent coeducation in universities in Fujian and Taiwan should be to improve students' practical skills and overall quality, enhance the strength of universities, improve the co-education conditions, set up a platform and arena for students' growth and development, and effectively jacking up the performance of talent co-education in universities. As per concrete situation of universities, some universities with similar conditions, matching professionalism and high strength should be sought for cooperation to explore common education projects with common interests as the link, jointly develop a talent co-education program, and further the practical cooperation in some areas, such as the training of teachers, design of curriculum and textbooks in two parties, R\&D strength and funds, and specialized technology breakthrough, etc. Therefore, on the premise that universities with better strength and higher comprehensive evaluation are chosen as partners, it is the move to raise their own strength to the higher level.

Strengthen policy support and macroeconomic regulation and control of government. The governments of Fujian and Taiwan should introduce relevant laws, regulations and policies to build a macro management system for the joint education of talents in universities and colleges in Fujian and Taiwan. However, it is not only controlled at the level of laws and policies, but also should be given sufficient policy support for the joint efforts of talents in Fujian and Taiwan. We will focus on cultivating joint education projects in the two places, formulate development plans, promote them in stages and in stages, and actively discuss with 
the government departments in Taiwan to fully mobilize the enthusiasm of the universities in the two places. In some necessary parts, political prejudice should be shelved, and appropriate legal support should be given to the talents of colleges and universities in Fujian and Taiwan, such as mutual recognition of credits between the two places and the participation of twins in Taiwan to participate in internships.

Change students' ideas and enhance learning motivation. That the SAT score is not good is the most popular reason why students in Fujian and Taiwan choose those universities in Fujian and Taiwan where coeducation system has been developed. Nevertheless, students in Fujian and Taiwan are indispensable part for the talent co-education system since they act as not only the executives but also the consumers. There is a need for completely focusing on the work and fully engaging in learning. It is necessary to change the students' learning beliefs, help and guide them to be aware of co-education features, thereby to improve their motivation to learn. Teachers and universities should know about students' interest appeals, teach them in accordance of their aptitude, urge them to learn from each other, and effectively improve the talent co-education performance in universities in Fujian and Taiwan.

Blend the concept of common education and rationalize the management system. Before the talent coeducation in Fujian and Taiwan universities, we must discuss and integrate the co-education concept. Only under the premise of consistent goals, can we effectively push the operation of the co-education system forward and create a co-education model with distinctive characteristics. Next, it is necessary to straighten out the internal management system, develop the management systems and specifications between the universities, achieve the level-to-level management, and clarify their respective duties and division of labor. Sub-sectors issue common education agreement specifications, specific programs for talent co-education, curriculum design, mutual recognition of grades, teaching content, instructional objectives, etc., and allocate the resources effectively and reasonably. As some students come from the mainland and spend most of time in the mainland when carrying out the co-education programs in Fujian and Taiwan universities, it is also suggested that the management be based on Fujian universities. Fujian universities should take more initiative to make the coeducation work deeper and meticulously, and strive for good co-education performance.

Build communication channels, facilitate deep integration. Among universities, due to the political and environmental impacts in Fujian and Taiwan, the talent co-education model in these areas is relatively sensitive, from the initial stage of common education, university selection, student recruitment and fund raising, objectives of common education, the determination of education programs, the selection of teachers and the mutual recognition of credits, to the co-education performance measurement in the later stages, all involve multi-parties' interests. They require mutual understanding and support from both parties. It is necessary to construct a smooth communication channel to jointly discuss and solve, only in this way can we launch a longterm development of talent co-education. Between the universities and the students, the smooth communication channel is the necessary guarantee for the universities to understand the students' learning and living conditions. The more perfect the communication mechanism, the more the sufficiency, applicableness and timeliness of the students are. The co-education performance can also be improved. All in all, the smooth communication channel is the premise of the deep integration between universities in Fujian and Taiwan. 


\section{References}

Anderson, J. C., \& Gerbing, D. W. (1988). Structural equation modeling in practice: A review and recommended two-step approach. Psychological Bulletin, 103(03), 411-423. https://doi.org/10.1037//00332909.103.3.411

Chen, W., Pan, W., \& Yang, Z. L. (2013). Impact mechanism of knowledge potential difference on knowledge governance Performance. Studies in Science of Science, 31(12), 1864-1871. http://dx.doi.org/10.3969/j.issn.1003-2053.2013.12.015

Chen, Y. X., Lin, C., Chen, Y. H., Su, S. J., Chen, B. F., \& Zhuang, P. F. (2015). Analysis on talent cultivation intergration mechansim of exchange students to Taiwan from the universities in Fujian-A case of exchange students from five universities in Fujian. Taiwan Agricultural Research, (6): 30-34. http://dx.doi.org/10.16006/j.cnki.twnt.2015.06.007

Chu, D. P., \& Li, H. F. (2016). Construction of long-term mechanism for cooperation between Fujian and Taiwan based on stakeholder perspective. Education Review, 6, 71-75.

Chu, D. P., \& Li, W. (2016). Construction of Long-term Mechanism of Cooperation between Fujian and Taiwan Based on Stakeholder Perspective. Educational Review, (6), 71-75.

Chu, D. P., Zheng, Y. X., \& Li, W. (2015). The macro background, operational form and innovation mode of the cooperation between Fujian and Taiwan_-Taking the Tourism Major of Fujian Strait Tourism College as an Example. Educational Review, (2), 130-133.

Guo, W, Liu, Y. R., \& Guo, B. (2014). The influence of partner selection and partnership on strategic performance in strategic alliance. Science \& Technology Progress and Policy, 31(5), 25-29. http://dx.doi.org/10.6049/kjjbydc.2013060119

Li, J., \& Li, W. (2017). Research on dynamic evaluation of collaborative innovation mechanism of human resources cultivation in colleges and universities in China. Southeast Academic Research, (1), 127-134.

Lian, X. R., Huang, M, \& Zhuang, M. S. (2018). The Current Situation, Dilemma and solutions of the complementation of higher education resources between Fujian and Taiwan. Journal of Fujian Agriculture and Forestry University, Philosophy and Social Sciences, 21(01), 81-85.

Liu, L. (2017). Research on management application of students in Fujian and Taiwan under the model of cooperation between Fujian and Taiwan. Journal of Taiyuan Urban Vocational and Technical College, (2), 78-79. http://dx.doi.org/10.3969/j.issn.1673-0046.2017.02.035

Liu, X. C., \& Lin, R. Z. (2014). A research on innovative model of Fujian-Taiwan jointly-run university education. Journal of Chongqing Three Gorges University, (6), 145-148. http://dx.doi.org/10.3969/j.issn.1009-8135.2014.06.034

Lv, Y. F. (2016). A probe into the ways of training innovative and entrepreneurial talents in fujian and taiwan universities under the mode of "School-Enterprise Cooperation". Straits Science, 5, 12-14. http://dx.doi.org/10.3969/j.issn.1673-8683.2016.05.004

Qian, X. Y. (2014). Research on the cooperative school running mode of colleges and universities in Fujian and Taiwan. Journal of Hunan Tax College, 6, 64-66. http://dx.doi.org/10.3969/j.issn.1008-4614.2014.06.022 
Wang, X. X., Jiang, X. H., Zhu, G. L., \& Xu, Z. (2018). Partner characteristics, partner relationships and synergic innovation performance_-An empirical study on "2011 Collaborative Innovation Center". Forum on Science and Technology in China, 4, 15-24.

Wen, Z. L., \& Ye, B. J. (2014). Analyses of mediating effects: The development of methods and models. Advances in Psychological Science, 5, 731-745. http://dx.doi.org/10.3724/SP.J.1042.2014.00731

Xiao, L. J. (2009). Fujian institute of education organizes research work on basic education in Taiwan. Journal of Fujian Education Institute, (9), 12-12. http://dx.doi.org/10.3969/j.issn.1674-5582.2009.09.071

Yan, H. (2016). Exploring new ways of cooperation in running schools between Fujian and Taiwan. Journal of Hunan Tax College, 29(1), 51-52. http://dx.doi.org/10.3969/j.issn.1008-4614.2016.01.016

Zhang, J. X. (2018). The connotation and essential features of performance evaluation of talent cultivation in colleges and universities. Educational Research, 39(03), 55-61.

Zhu, G. H., Chen, W. M., Cai, R. L., \& Qian, Y. Y. (2014). Influencing factors and evolution mechanism of enterprise graduate workstation talent training performance. Higher Education Research, 6, 59-67. 